\title{
Knowledge, Attitude and Practice of Diabetes Mellitus Type 2 Patients towards Compliance to Treatment in Pusat Kesehatan Masyarakat
}

\author{
Asila Zahiri binti Zahari, ${ }^{1}$ Vycke Yunivita K.D, ${ }^{2}$ Januar Wibawa Martha ${ }^{3}$ \\ ${ }^{1}$ Faculty of Medicine, Universitas Padjadjaran, ${ }^{2}$ Departmen of Pharmacology \& Therapy Faculty \\ of Medicine Universitas Padjadjaran, ${ }^{3}$ Department of Cardiovascular Faculty of Medicine \\ Universitas Padjadjaran/Dr. Hasan Sadikin General Hospital, Bandung
}

\begin{abstract}
Background: Diabetes mellitus (DM) is one of the top ten chronic diseases in the world and the prevalence of this disease will increase in the future including in Indonesia. Treatment of DM needs collaboration between the patients and the providers to prevent multiorgan complications and increase the compliance to treatment. The correlation among the level of knowledge (K), attitude (A) and practice (P) plays an important role of patients towards compliance to treatment. The objectives of this study was to identify the level of knowledge, attitude and practice of DMT2 patient towards compliance to treatment at a primary care facility.

Methods: This study was carried out by using cross sectional descriptive study from August until November 2013 in Public Health Center (Pusat Kesehatan Masyarakat/Puskesmas) Tanjungsari, Sumedang, West Java. There were 49 respondents and the sampling method used was non-probability sampling. The data was collected through face to face interview using questionnaire which consist of 27 questions about knowledge, attitude and practice. The collected data was anayzed using computer and was presented in the form of tables and a figure.

Results: This study discovered that 22 patients had moderate knowledge, 17 patients had good knowledge and 10 patients had poor knowledge. As for attitude, there were 32 patients had good attitude and 17 patients had moderate attitude. Whereas, for practice, 44 patients were good and 5 patients were moderate. Conclusions: Majority of respondent had moderate knowledge, good attitude and practices. [AM].2016;3(3):416-20]
\end{abstract}

Keywords: Attitude, compliance to treatment, diabetes mellitus type 2, knowledge, practice

\section{Introduction}

The prevalence of diabetes mellitus (DM) was 171 million people in the year 2000 and is expected to increase to 366 million people in the year 2030 worldwide. ${ }^{1}$ Diabetes mellitus is divided into two types, which are DM type 1 (DMT1) and DM type 2 (DMT2). The last type (DMT2) accounts about $90 \%$ of all DM cases in the world. ${ }^{2}$ The DMT2 is a metabolic disorder that relates with increase of blood sugar level and other vital risk concerning blood pressure, cholesterol and coagulation. ${ }^{3}$ Indonesia is counted at number four of 10 countries with diabetes after India, China and United States of America (USA) and accordingly, is predicted that there will be about 21.3 million people with DM in the year $2030 .^{1}$
According to a report from Ministry of Health of Indonesia or Riset Kesehatan Dasar (RISKESDAS) 2007, the frequency of diabetes in Indonesia was 5.7\%, which 70\% of them were not properly diagnosed. ${ }^{4}$ When the disease is poorly controlled, it will affect multiple organ disorders such as kidney, brain, heart and eyes that contribute to higher morbidity and mortality. 5,6

The development and acceleration of diabetic complication are due to patient's non-compliance to treatment that lead to the insufficiency of metabolic control. ${ }^{7}$ Since DMT2 is associated with complication that influence many organ systems, they may have great effect on the patient's quality of life. ${ }^{8}$ The complication ultimately lead to increase the health care visits and cost. ${ }^{5}$

Diabetes care of DMT2 patients focuses on

Correspondence: Asila Zahiri binti Zahari, Faculty of Medicine, Universitas Padjadjaran, Jalan Raya Bandung-Sumedang Km.21, Jatinangor, Sumedang, Indonesia, Phone: +62 81910344530 Email: asila_zahiri@yahoo.com.my 
Asila Zahiri binti Zahari, Vycke Yunivita K.D, Januar Wibawa Martha: Knowledge, Attitude and Practice of 417 Diabetes Mellitus Type 2 Patients towards Compliance to Treatment in Pusat Kesehatan Masyarakat

improving quality of life through controlling glycemic index, risk factor control, changes in lifestyle, education about diabetes and complication prevention. ${ }^{2}$ DM education is the key element of diabetes care..$^{2,9}$

Since the management is complicated, proper training of both DM patients and primary care providers can bring a great advantage. ${ }^{2}$ The ability to attain treatment goals is suggested with lifestyle changes and drug therapy correlated with general knowledge about treatment and risk factor. ${ }^{8}$ The knowledge and skills of patients can affect their compliance to treatment. ${ }^{8}$ Medication compliance is found highly correlated with attitudes and beliefs towards medication.8 Treatment failure is commonly believed due to non-compliance. ${ }^{7}$

Since DM requires long life treatment, DM patients need more discipline in their compliance of drugs in daily basis. Only about fifty percent of DMT2 patients that comply with long term treatment has been showed. This also may cause disadvantageous to patients on compliance of anti-diabetes drugs, The correlation among the level of knowledge $(\mathrm{K})$, attitude $(\mathrm{A})$ and practice $(\mathrm{P})$ plays an important role of patients towards compliance to treatment. In regard to this situation, the objectives of this study were to identify the level of knowledge, attitude and practice of DMT2 patient towards compliance to treatment at a primary care facility.

\section{Methods}

The study design was cross-sectional descriptive study and conducted in October 2013 in Public Health Center (Pusat Kesehatan Masyarakat/Puskesmas) Tanjungsari, Sumedang, West Java. A total of 50 respondents of DMT2 patients were involved in this study. All procedures in this study were performed after being approved by Health Research Ethics Committee, Faculty of Medicine Universitas Padjadjaran.

Patients with gestational Diabetes Mellitus (GDM) and mentally incompetent were excluded from the study. Sampling technique was purposive non-probability. The respondents were given explanation about aim of the study. Respondents that were willing to participate were required to fill the informed consent form. Respondents were directly interviewed by using questionnaire which consist of 27 questions regarding Knowledge, Attitude and Practice of DMT2 patients towards compliance to treatment. The total score of each variable was classified into 3 categories: 1) Knowledge: good $(76-100 \%)$, moderate $(56-75 \%)$ and poor $(\leq 65 \%), 2)$ Attitude: good

Table 1 Respondent's Characteristics

\begin{tabular}{lcc}
\hline \multicolumn{1}{c}{ Variables } & Number (n=49) & Percentage (\%) \\
\hline Gender & 23 & \\
Male & 26 & 46.94 \\
Female & & 53.06 \\
Age group (years old) & 15 & \\
38-48 & 15 & 30.61 \\
49-58 & 10 & 30.61 \\
59-67 & 9 & 20.41 \\
68-77 & & 18.37 \\
Education level & 13 & \\
Elementary School & 20 & 26.53 \\
Junior High School & 16 & 40.82 \\
Senior High School & & 32.65 \\
Diabetes duration (years) & 39 & \\
1-7 & 5 & 79.59 \\
8-14 & 5 & 10.20 \\
15-20 & & 10.20 \\
\hline
\end{tabular}




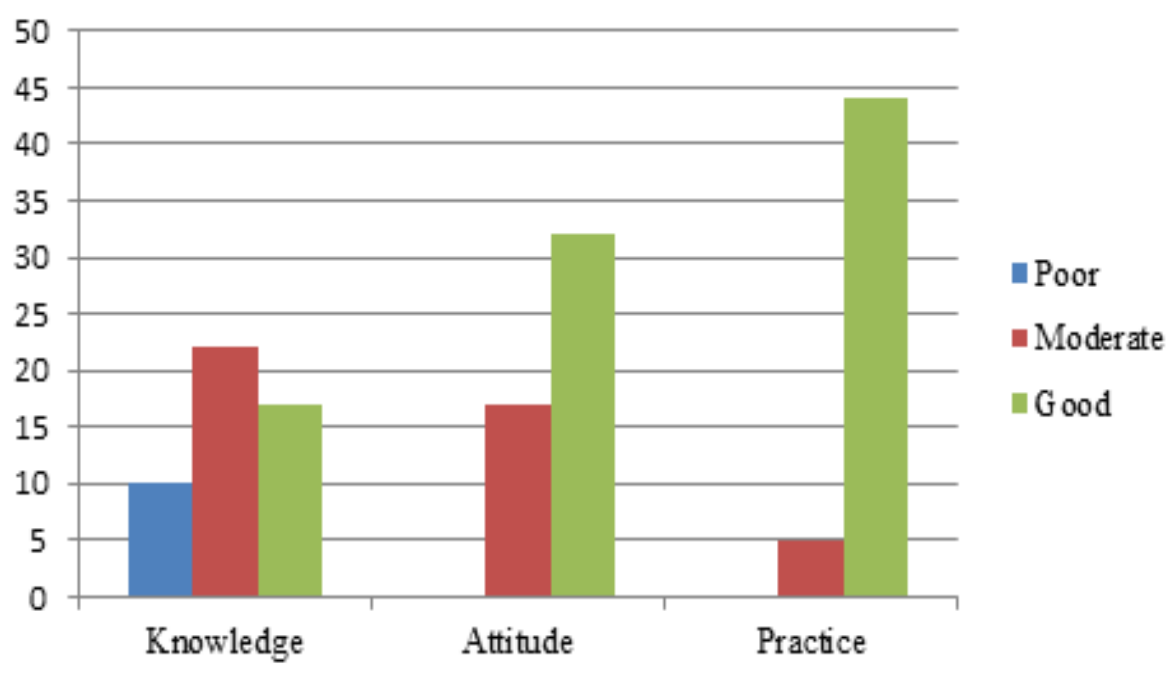

Figure 1 Knowledge, Attitude and Practice of DM type 2 Patients towards Compliance to Treatment in Puskesmas Tanjungsari

( $>6$ points), moderate (3-6 points) and poor ( $<3$ points), 3) Practice: good ( $>12$ points), moderate (6-12 points) and poor ( $<6$ points).

The collected data was analyzed by using statistical product and service solution software and Microsoft excel and presented in the form of table and bar chart.

\section{Results}

From 50 respondents, only 49 respondents participated in this study. This study discovered that more female had DMT2 compared to male. The average age for patients was between 3848 years old and 49-58 years old. Education level of DMT2 patients who came to Puskesmas Tanjungsari was Junior High School and most of the patients have had diabetes for about 1-7 years (Table 1).

DMT2 patients who came to Puskesmas
Tanjungsari mostly had hypertension and family member who had DMT2 (Table 2). Most of the respondents did not exercise regularly.

From 49 DMT2 patients who came to Puskesmas Tanjungsari, most of them had moderate knowledge, good attitude and good practive (Figure 1).

\section{Discussion}

The result of the study showed that, the respondents mostly had middle school education which was up to $40.82 \%$, the second largest group was from high school $(32.65 \%)$ and lastly was from primary school $(26.53 \%)$. This showed that most of the subjects came from similar community and social background. The risk factors for DMT2 patients in this study, such as hypertension, family history of diabetes and physical

Table 2 Risk Factors of DM type 2 Patients in Puskesmas Tanjungsari

\begin{tabular}{lcccc}
\hline & \multicolumn{5}{c}{ Response } \\
\cline { 2 - 6 } \multicolumn{1}{c}{ Statements } & \multicolumn{2}{c}{ Yes } & No \\
\cline { 2 - 6 } & n & \% & $\mathbf{n}$ & \% \\
\hline Exposure on DM & 16 & 32.65 & 33 & 67.35 \\
Smoking & 17 & 34.69 & 32 & 65.31 \\
Hypertension & 31 & 63.27 & 18 & 36.73 \\
Family History & 25 & 51.02 & 24 & 48.98 \\
Exercise & 8 & 16.33 & 41 & 83.67 \\
\hline
\end{tabular}


inactivity contribute to the frequency of DMT2. ${ }^{10}$ Most of the respondents were only having under moderate level of knowledge. The knowledge about compliance of drugs include dosage, time taken and side effects of DM medication. According to Notoatmodjo ${ }^{11}$ knowledge can be grouped into 6 levels of domain cognitive which are important to take action. As for this research, DMT2 patients who came to Puskesmas Tanjungsari, were given information regarding disease and compliance of drugs prescribed from the doctor they should take. Other than that, laboratory workers would always be there if patients wanted to have regular check-up like blood glucose test. According to American Diabetes Association (ADA), someone will be diagnosed as DM patient if the fasting plasma glucose is $\geq 7.0 \mathrm{mmol} / \mathrm{l}$ or $126 \mathrm{mg} / \mathrm{dl}^{10}$

Beside checking the glucose level routinely to DMT2 patients, laboratory workers also would give them knowledge regarding their condition and what should they do based on their current condition. ${ }^{12}$ Instead of compliance towards medication, patient's lifestyle changes and risk factor should be controlled. ${ }^{2}$ The doctor and the laboratory workers in Puskesmas Tanjungsari would also use understandable non-medical term language when they explained to DMT2 patients. ${ }^{12}$ It was needed to make sure that the DMT2 patients who came to Puskesmas Tanjungsari understood the given instructions. One of the factors that affected the compliance of patients was quality interaction between professional healthcare and patients. ${ }^{12}$ In the level of knowledge, knowing is the first. Patients can develop their knowledge by being given good information. Understanding or comprehension is the second level of knowledge, here, patients were able to describe concisely about compliance of drugs that have been informed to them. The third level is application, which is DMT2 patients' ability to apply their knowledge that they get from the doctor by following directions and instructions in terms of dosage, time taken for drugs and precautions when taking drugs. The level of knowledge then, followed by analysis, synthesis and evaluation which was resulted, when majority DMT2 patients who came to Puskesmas Tanjungsari had moderate and some good knowledge level. Patients' educational background also plays an important to knowledge. This was shown from study by Sweileh et al. ${ }^{13}$, it was stated that educated people with higher education were more conscious of the result of non-compliance and amount of compliance.
Other research by Mahfouz and Awadalla ${ }^{14}$ stated that lower regimen compliance high number diabetes morbidity related with low socioeconomic status and low education level. This is related with patients' understanding on what the doctors and laboratory workers informed them. It is concluded, that there were also some of DMT2 patients that did not understand the given information.

The level of good attitude of DMT2 patients in compliance of drugs was more than $50 \%$. Attitudes is from stimulation or respond from someone. ${ }^{11}$ For example, the reaction of DMT2 patients when they were diagnosed. Patients' attitudes towards compliance of DM treatment are based on dosage, complication and side effects. On this research, DMT2 patients who came to Puskesmas Tanjungsari knew and understood about compliance of treatment they were taking. It showed various attitudes towards compliance of drugs. Attitude itself can be divided into 4 levels, the lowest is receiving, and the highest level is responsible. ${ }^{11}$ As this research illustrated, DMT2 patients who came to Puskesmas Tanjungsari felt responsible in terms of taking DM medication. As for knowledge, this important role is only obtained through education. ${ }^{9}$ They could get it from consultation that organized by Puskesmas Tanjungsari. According to Notoatmodjo ${ }^{11}$ attitudes consists of trust, emotion and action. It is shown in this research that the knowledge of patients was mostly moderate, however, the attitude was good. Therefore, it was related with one of the component stated by Notoatmodjo ${ }^{11}$ which is the DMT2 patients' beliefs towards compliance of medication. ${ }^{8}$ It is also shown in other study in an urban area of South India ${ }^{15}$ that if the patient were having high risk and affected with diabetes, they would change their behaviour and attitude on diabetes accordingly.

It is also shown that the practice level of DM patients from time taking, health control and dosage towards compliance DM medication. Most of DMT2 patients who came to Puskesmas Tanjungsari had good practice. The characteristic of drugs that is well known also made the patients trust the medication. Patients followed the rules of dosage drugs intake. It can be stated, that most of the patients followed the instructions because patients understand the instructions, dosage, side effects and complications of drugs intake. Based on Stimulus Organism Theory (S-O-R), practice will appear when the comprehension and understanding change into an attitude by stimulus. ${ }^{11}$ It is deducted 
that based on Notoatmodjo $0^{11}$ patients behave based on what the doctor told them and trust the effectiveness of drugs they were taking. Other than that, they were getting support and motivation from health practitioners, family and friends. It is also stated in study by Kasznicki et al. ${ }^{7}$ that advantage role to increase quality of compliance is also support provided by family and friends. ${ }^{7}$ Therefore, it made the DMT2 patients who came to Puskesmas Tanjungsari have good practices in compliance towards drugs. This is one of the components that play important role towards compliance of DM medication.

The process of DMT2 patients toward compliance of drugs includes 3 elements. They are knowledge $(\mathrm{K})$, attitude $(\mathrm{A})$ and practice (P), all applied toward their compliance on DM medication. In conclusion, among 49 respondents, the level of knowledge of DMT2 patients was moderate. Meanwhile, for the attitude level, most of the patients were having good attitude and practice.

Education program should be conducted to increase awareness for DMT2 patients. Other than that, education of health and illness about DM should be done to increase the level of knowledge of DM patients, since knowledge is an important factor to influence someone's attitude and practice. The limitations in this study were the time available for data collection and data analyzed. Since the sample is small, it is recommended to increase the sample amount as a suggestion for other researcher who would like to do further research study or in the same field.

\section{References}

1. Wild S, Roglic G, Green A, Sicree R, King H. Global prevalence of diabetes: estimates for the year 2000 and projections for 2030. Diabetes Care. 2004;27(5):1047-53.

2. Gul N. Knowledge, attitudes and practices of type 2 diabetic patients. J Ayub Med Coll Abbottabad. 2010;22(3):12-31.

3. Blackburn DF, Swidrovich J, Lemstra M. Non-adherence in type 2 diabetes:practical considerations for interpreting the literature. Patient Prefer Adherence. 2013;7:183-9.

4. Widyahening IS, Soewondo P. Capacity for management of type 2 diabetes mellitus in primary health centers in Indonesia. J Indon Med Assoc. 2012;62(11):439-43.

5. Marian AO, Joy IO. Knowledge, attitudes and practices of people with type 2 diabetes mellitus in tertiary health care centre, Umuahia, Nigeria. J Diabetes Metab. 2012;3(3):1-4.

6. Khattab M, Khader YS, Al-Khawaldeh A, Ajlouni K. Factors associated with poor glycaemic control among patients with type 2 diabetes. J Diabetes Complications. 2010;24(2):84-9.

7. Kasznicki J, Glowacka A, Drzewoski J. Type 2 diabetic patients compliance with drug therapy and glycaemic control. Diabetologia. 2007;7(4):199-203.

8. Kheir N, Greer W, Yousif A, Geed AI, Okkah RA. Knowledge, attitude and practices of Qatari patients with type 2 diabetes mellitus. J Pharm Pract. 2011;19(3):18591.

9. Shah VN, Kamdar PK, Shah N. Assessing the knowledge, attitudes and practice of type 2 diabetes among patients of Saurashtra region, Gujarat. Int J Diabetes Dev Ctries 2009;29(3):118-22.

10. Kasper DL, Fauci AS, Longo DL, Braunwald E, Hauser SL, Jameson JL. Harrison's principles of internal medicine. $16^{\text {th }}$ ed. New York: McGraw-Hill; 2005.

11. Notoatmodjo PDS. Promosi kesehatan dan ilmu perilaku. $1^{\text {st }}$ ed. Jakarta: PT Rineka Cipta; 2007.p.249

12. Niven N. Psikologi kesehatan pengantar untuk perawat dan profesional kesehatan lain. 2nd ed. Jakarta: EGC; 2012.p.345

13. Sweileh WM, Aker O, Hamooz S. Rate of compliance among patients with diabetes mellitus and hypertension. An-Najah Univ J Res (N.Sc). 2005;19:1-12.

14. Mahfouz EM, Awadalla HI. Compliance to diabetes self-management in rural ElMinia, Egypt. Cent Eur J Public Health. 2011;19(1):35-41.

15. Hawal NP, Shivasmamy, Kambar S, Patil S, Hiremath MB. Knowledge, attitude and behaviour regarding self-care practices among type 2 diabetes mellitus patients residing in an urban area of South India. International Multidisciplinary Research Journal. 2012;2(12):31-5. 